\title{
Roles of microRNA on cancer cell metabolism
}

\author{
Bing Chen ${ }^{1 \dagger}$, Hongbin $\mathrm{Li}^{1+}$, Xiao Zeng ${ }^{1}$, Pengbo Yang ${ }^{1}$, Xinyu Liu ${ }^{1}$, Xia Zhao ${ }^{1,2}$ and Shufang Liang ${ }^{1 *}$
}

\begin{abstract}
Advanced studies of microRNAs (miRNAs) have revealed their manifold biological functions, including control of cell proliferation, cell cycle and cell death. However, it seems that their roles as key regulators of metabolism have drawn more and more attention in the recent years. Cancer cells display increased metabolic autonomy in comparison to non-transformed cells, taking up nutrients and metabolizing them in pathways that support growth and proliferation. MiRNAs regulate cell metabolic processes through complicated mechanisms, including directly targeting key enzymes or transporters of metabolic processes and regulating transcription factors, oncogenes / tumor suppressors as well as multiple oncogenic signaling pathways. MiRNAs like miR-375, miR-143, miR-14 and miR-29b participate in controlling cancer cell metabolism by regulating the expression of genes whose protein products either directly regulate metabolic machinery or indirectly modulate the expression of metabolic enzymes, serving as master regulators, which will hopefully lead to a new therapeutic strategy for malignant cancer. This review focuses on miRNA regulations of cancer cell metabolism,including glucose uptake, glycolysis, tricarboxylic acid cycle and insulin production, lipid metabolism and amino acid biogenesis, as well as several oncogenic signaling pathways. Furthermore, the challenges of miRNA-based strategies for cancer diagnosis, prognosis and therapeutics have been discussed.
\end{abstract}

Keywords: MicroRNA, Cell metabolism, MiRNA biomarker

\section{Background}

MicroRNAs (miRNAs) are endogenous $\sim 22$ nt RNAs that can play important regulatory roles in a variety of biological processes. They are genome-encoded, endogenous negative regulators of translation and mRNA stability originating from long primary transcripts with local hairpin structures [1]. Conserved seed pairing indicates that over one third of human genes appear to be conserved miRNA targets [2]. MiRNAs are involved in cell proliferation, intercellular signaling, cell growth, cell death $[3,4]$, cellular differentiation, apoptosis [5] and cellular metabolism [6,7]. Meanwhile they have emerged as key post-transcriptional regulators of gene expression, and their dysregulation may lead to abnormal gene expression, which is associated to human diseases such as cancer. For example, miR-378* (expressed from the 3 '-arm), which mediates metabolic shift in breast cancer cells, leading to a reduction in tricarboxylic acid cycle gene expression and oxygen consumption as well as an increase

\footnotetext{
* Correspondence: zizi2006@scu.edu.cn

${ }^{\dagger}$ Equal contributors

'State Key Laboratory of Biotherapy, West China Hospital, Sichuan University, No.17, third section of Renmin South Road, Chengdu 610041, People's

Republic China

Full list of author information is available at the end of the article
}

in lactate production, via the PGC-1 $1 /$ ERR $\gamma$ transcriptional pathway [8].

Recent studies have shown that miRNAs play important roles in energy metabolism, including glucose and lipid metabolism and amino acid biogenesis [9] (Table 1). Besides, miRNAs are also able to recognize and modulate metabolic factors in transcriptional levels, relevant both in non-neoplastic and in cancer cells [10]. The altered metabolism of tumor cells may be a potential means to evade programmed cell death in order to favor survival and growth. The best characterized metabolic phenotype observed in tumor cells is the Warburg effect, in which the deregulation of miRNAs contributes to high glycolysis $[11,12]$.

MiRNAs participate in controlling cancer cell metabolism by regulating the expression of genes whose protein products either directly regulate metabolic machinery or indirectly modulate the expression of metabolic enzymes, serving as master regulators. Generally, miRNA signatures may distinguish physiological, pathologic from cancerous states, which could be useful biomarkers in targeted therapeutic-diagnostics for cancer. Therefore, this review will focus on discussing the important roles of miRNA 
Table 1 Summary of miRNA regulation in energy metabolism

\begin{tabular}{|c|c|c|c|c|}
\hline miRNA & Tissue / cell lines & miRNA functions & Target gene/Pathway & Reference \\
\hline $\begin{array}{l}\mathrm{miR}-103 / \\
107\end{array}$ & $\begin{array}{l}\text { obese mice: ob/ob mice } \\
\text { and diet-induced-obese (DIO) C57BL/6J mice }\end{array}$ & regulate insulin sensitivity & caveolin-1 & 41 \\
\hline miR-122 & $\begin{array}{l}\text { primary mouse hepatocytes } \\
\text { and AML12 }\end{array}$ & $\begin{array}{l}\text { regulator of cholesterol and } \\
\text { fatty-acid metabolism }\end{array}$ & & $23,26,38,49,5054,60$ \\
\hline miR-133 & 293FT cells & $\begin{array}{l}\text { decreased GLUT4 expression } \\
\text { and reduced insulin-mediated } \\
\text { glucose uptake in cardio } \\
\text { myocytes }\end{array}$ & & 31,34 \\
\hline miR-14 & Drosophila & regulate fat metabolism & & 36 \\
\hline miR-143 & liver of obese mouse models & $\begin{array}{l}\text { impairs insulin-stimulated } \\
\text { AKT activation and glucose } \\
\text { homeostasis }\end{array}$ & Orp8 / Akt pathway & $12,26,35,36,37,91$ \\
\hline miR-146 & diabetic $\mathrm{db} / \mathrm{db}$ mice islets / MIN6B1 cells & cell death & Irak1 \& Traf6 / AP-1 pathway & 52 \\
\hline $\begin{array}{l}\operatorname{miR}-15 a / \\
16-1\end{array}$ & $\begin{array}{l}\text { leukemic cell line model (MEG-01) } \\
\text { and in primary CLL samples }\end{array}$ & $\begin{array}{l}\text { directly or indirectly affect } \\
\text { apoptosis and cell cycle }\end{array}$ & MCL1, BCL2, ETS1, or JUN & 27 \\
\hline miR-195-5p & bladder cancer T24 cells & $\begin{array}{l}\text { inhibited cell growth and } \\
\text { promoted cell apoptosis } \\
\text { through suppression of } \\
\text { GLUT3 expression }\end{array}$ & & 25 \\
\hline miR-210 & $\begin{array}{l}\text { human pulmonary arterial endothelial cells } \\
\text { (HPAECs) }\end{array}$ & $\begin{array}{l}\text { cellular metabolism and } \\
\text { adaptation to cellular stress }\end{array}$ & ISCU1/2 & 42 \\
\hline $\mathrm{miR}-23 \mathrm{a} / \mathrm{b}$ & human P-493 B cells & $\begin{array}{l}\text { regulate expression of } \\
\text { glutaminase and glutamine } \\
\text { metabolism }\end{array}$ & $c-M y c$ & 6 \\
\hline miR-277 & D. melanogaster & $\begin{array}{l}\text { a metabolic switch controlling } \\
\text { amino acid catabolism }\end{array}$ & & 61 \\
\hline \multirow[t]{2}{*}{$\operatorname{miR}-27 a$} & 3Т3-L1 & $\begin{array}{l}\text { suppress adipocyte } \\
\text { differentiation }\end{array}$ & PPARY & 51 \\
\hline & Male C57BL/6J mice and 3T3-L1 cells & $\begin{array}{l}\text { a negative regulator of } \\
\text { adipocyte differentiation }\end{array}$ & & \\
\hline miR-29b & human kidney cells (HEK293) & $\begin{array}{l}\text { control metabolic pathway } \\
\text { of amino acid catabolism }\end{array}$ & mRNA for DBT & 62 \\
\hline miR-335 & liver of obese mouse & $\begin{array}{l}\text { affects adipocyte } \\
\text { differentiation } \\
\text { and lipid accumulation }\end{array}$ & PPARY \& aP2 & 53 \\
\hline miR-33a/b & mouse peritoneal macrophages & $\begin{array}{l}\text { regulate both } \mathrm{HDL} \text { biogenesis } \\
\text { in the liver and cellular } \\
\text { cholesterol efflux }\end{array}$ & $\mathrm{ABCA} 1$ & 58 \\
\hline miR-34a & diabetic $\mathrm{db} / \mathrm{db}$ mice islets / MIN6B1 cells & $\begin{array}{l}\text { sensitization to apoptosis } \\
\text { and impaired nutrient-induced } \\
\text { secretion }\end{array}$ & Bclll / p53 pathway & 52,68 \\
\hline miR-370 & liver of mouse & affects lipid metabolism & Cptla & 54 \\
\hline miR-375 & pancreatic endocrine cells (MIN6 cells) & $\begin{array}{l}\text { suppressed glucose-induced } \\
\text { insulin secretion }\end{array}$ & Mtpn & 45,76 \\
\hline \multirow[t]{4}{*}{ miR-378 } & NMuMG cells and NT2196 & $\begin{array}{l}\text { reduce tricarboxylic acid cycle } \\
\text { gene expression and oxygen } \\
\text { consumption as well as } \\
\text { increase } \\
\text { lactate production }\end{array}$ & ERRY and GABPA & 8 \\
\hline & INS-1E cells/primary rat islets & $\begin{array}{l}\text { decreased glucose-stimulatory } \\
\text { action on insulin gene } \\
\text { expression } \\
\text { and DNA synthesis }\end{array}$ & & \\
\hline & & Cell growth & Eeflel & 76 \\
\hline & & cell growth & Cadm 1 & 76 \\
\hline
\end{tabular}




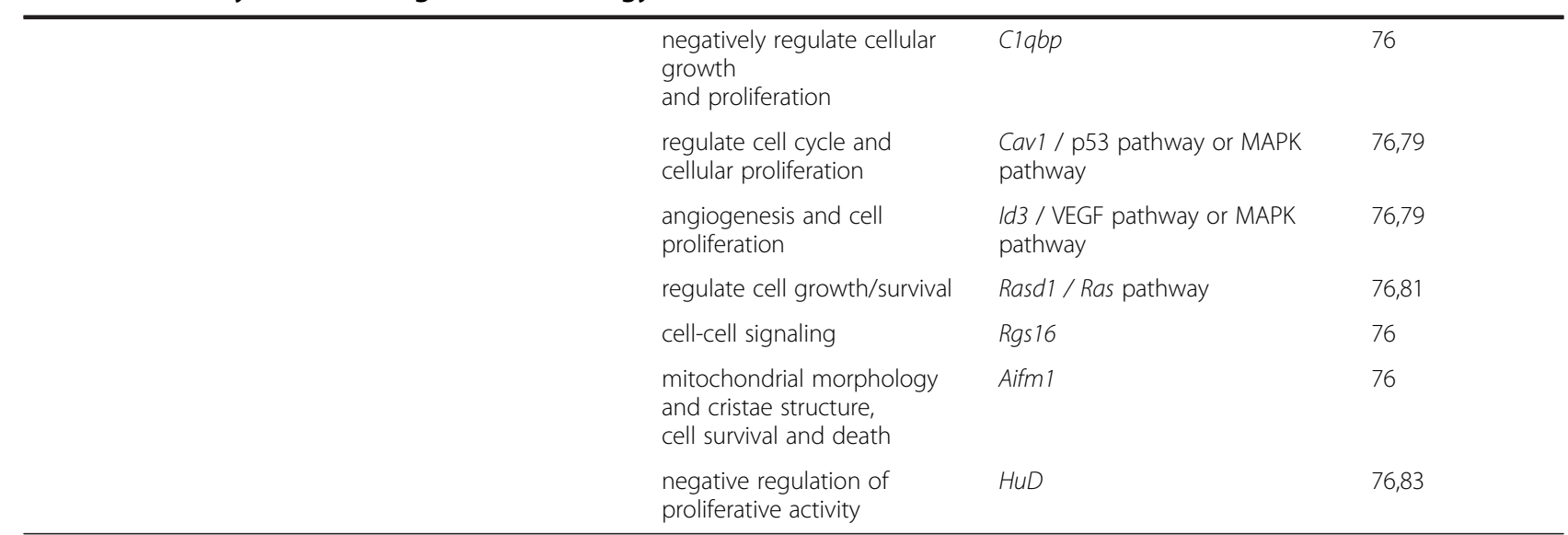

expression and deregulation in the altered metabolism in cancer cells.

\section{MiRNAs involved in cancer cell metabolism}

The biogenesis of miRNAs is tightly associated with their action mechanism (Figure 1). Most miRNAs derived from independent transcription units [13,14] and are encoded by a bewildering array of genes. Their transcription is typically performed by RNA polymerase II, with transcripts capped and polyadenylated. The resulting primary or pri-miRNA transcript extends both 5 ' and 3' from the miRNA sequence. The sequential processing reaction excises the stem-loop from the remainder of the transcript to create a pre-miRNA product, which occurs in the nucleus and is mostly carried out by a nuclear member of the RNase III family (Drosha). The following step excises the terminal loop from the premiRNA stem to create a mature miRNA duplex of approximately 22 bp length, which is carried out by the canonical Dicer enzyme in the cytoplasm. Either of the strands becomes stably associated with RNA-induced silenced complex (RISC), which can be called miRISC complex $[15,16]$. The miRISC complex acts as a regulator of target gene by specially recognizing and regulating particular mRNAs to inhibit target genes [17].

A shift in glucose metabolism from oxidative phosphorylation to aerobic glycolysis was a key biochemical hallmark of tumor cells $[18,19]$. The altered metabolism was called "Warburg phenomenon", which consists of an increase in glycolysis maintained in conditions of high oxygen tension and gives rise to enhanced lactate production $[20,21]$. Metabolic shift in cancer cells seems to be influenced by oncogene and tumor suppressor networks [22]. What's more, most of these tumor suppressors are miRNA targets. For example, phosphatidylinositol 3-kinase, a lipid kinase that regulates the levels of phosphorylated phosphatidylinositol at the plasma membrane, plays a key role in cancer cell metabolism, which is targeted by miR-320, miR-123a, miR-422, miR-506 and miR-136.

There are several lines of evidence that many key molecules in cell metabolism are miRNA targets, thus giving a clue that miRNA regulates cell metabolism. Since miRNAs regulate a substantial fraction of genes in animal genomes, Tibiche and Wang systematically analyzed the human metabolic network by integrating miRNA target genes into the network [23]. They performed randomization tests to determine whether a multiple-gene-node is significantly regulated by miRNAs and defined 79 multiple-gene-nodes as miRNA targets. They merged the miRNA targets of single-gene-nodes with the multiple-gene-nodes, and found that 238 (22\%) nodes are miRNA targets. The functional association analysis of miRNAs and metabolic pathways uncovered that miRNAs predominantly regulate central metabolic pathways such as amino acid biosynthesis, certain sugar and lipid metabolism (Figure 2).

\section{Regulation of metabolic activity by miRNAs}

MiRNAs regulate cell metabolic processes through complicated mechanisms, including directly targeting key molecules (transporters or enzymes / kinases) of metabolic processes and regulating multiple oncogenic signaling pathways (Figure 3). MiRNAs could directly modulate the expression of metabolic transporters or enzyme activities. In addition, MiRNAs also play pivotal roles in the expression level of transcription factors and oncogenes or tumor suppressors, including p53, c-Myc, AMPK and AKT signaling pathway.

The molecular mechanisms driving the Warburg effect in cancer cells were taken as an example to explain miRNA regulation in energy metabolism. As shown in Figure 3, several miRNAs affect gene transcription and expression of glucose transporters (GLUTs) which are responsible for transporting glucose into cytoplasm. In the initial step of glucose metabolism, glucose could be 


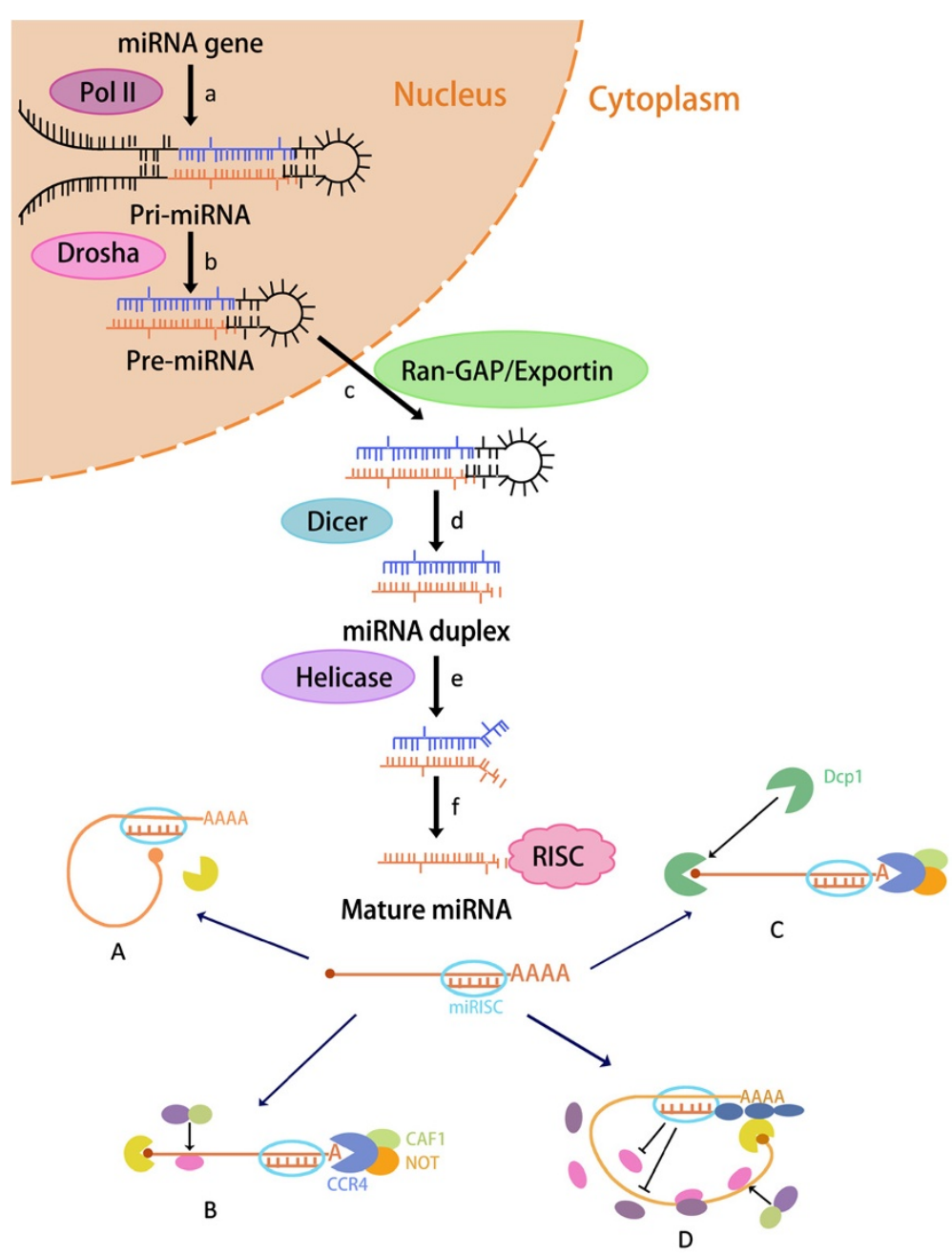

Figure 1 Biological functions of miRNA. The first step is the nuclear cleavage of the pri-miRNA, with a 60-70 nt stem loop intermediate liberated, known as the miRNA precursor, or the pre-miRNA. Then this pre-miRNA is actively transported from the nucleus to the cytoplasm by Ran-GTP and export receptor. One end of the mature miRNA was cut by Drosha in nuclear and the other end is processed in the cytoplasm by the enzyme Dicer. Either of the strands becomes stably associated with RNA-induced silenced complex (RISC), which can be called miRISC complex. The miRISC complex inhibits the target genes by $(\mathbf{A})$ repressing initiation at the cap recognition, (B) inducing deadenylation of mRNA and thereby inhibiting circularization of mRNA, (C) inducing ribosomes to drop off prematurely thus repressing the translation initiation and (D) promoting mRNA degradation.

transported over a plasma membrane by GLUT3 or GLUT4 which is a target of miR-133 [24] or miR-195-5p [25]. Thus, miRNAs could directly regulate intracellular glucose levels. In the following step, the hexokinase 2 (HK2), the first rate-limiting enzyme of glycolysis, is among the top list of genes predicted and potentially regulated by multiple miRNAs including miR-143 [26]. Along the glycolysis reaction chain, fructose 1,6-bisphosphate is broken down into glyceraldehyde 3-phosphate and dihydroxyacetone phosphate, which is catalyzed by aldolase A (Aldo A) in the reversible aldol reaction. While the enzyme Aldo A is down-regulated by miR-15a/16-1cluster [27]. And the specific miRNAs in glucose metabolism will be summarized into 4 subtitles as follows, including
miRNA effects on glucose uptake, glycolysis, tricarboxylic acid (TCA) cycle and insulin regulation.

On the other hand, aerobic glycolysis in tumor cells is driven by multiple miRNA-involved oncogenic signaling pathways. For example, AKT, a cardinal node in diverse signaling cascades, is regulated by miR-21 [28], which stimulates glycolysis by directly regulating glycolytic enzymes and activating downstream mammalian target of rapamycin (mTOR) activity. The regulation of several specifically signaling pathways involved in cancer cell metabolism by miRNAs will be introduced in detail in the second section of this review. Therefore, mRNA dysregulation in any step of metabolic processes contributes to metabolic abnormalities and even cancer development. 


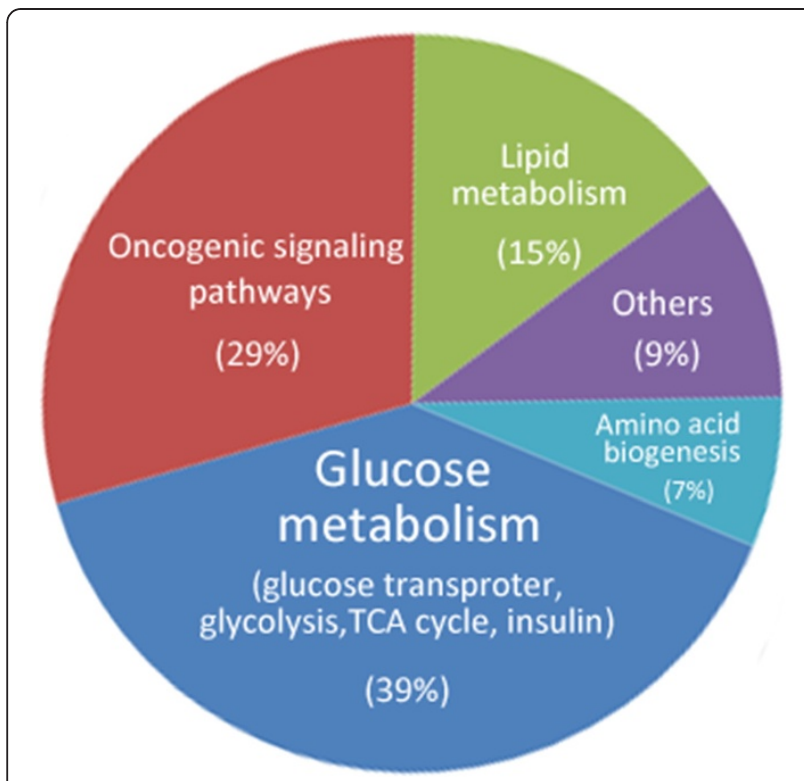

Figure 2 The main miRNAs involved in metabolism of glucose, lipid and amino acid, as well as metabolism-associated oncogenic signaling pathways. Among the total 60 miRNAs mentioned in the text, more than 20 miRNAs, including miR-375, miR-133, miR-199a, miR-138, etc., involve in glucose metabolism. And miR-14, miR-27a, miR-34a, miR-146, miR-335, miR-370, miR-122 and miR-33a/b function on lipid metabolism, including participating in controlling Acetyl-CoA and plasma cholesterol. While several miRNAs (miR-23b*, miR-29a/b, miR-277 etc.) play functions in amino acid metabolism mainly through regulating acyltransferase and aketoacid dehydrogenase. In addition, about $29 \%$ of the mentioned miRNAs (miR-125b, miR-504, miR-25, miR-30d, etc.) participate in metabolism-associated oncogenic signaling pathways.

\section{MiRNAs regulate glucose metabolism \\ MiRNAs affect glucose uptake}

GLUTs (or SLC2A) are a wide group of membrane proteins that facilitate the transport of glucose over a plasma membrane in most mammalian cells. To date, 14 members of GLUTs have been identified [29]. The amounts of the GLUT1, GLUT2, and GLUT3 transcripts were elevated in most cancer tissues, while mRNA levels of GLUT4 and GLUT5 were below sensitivity in these cancer tissues. The potential effects of the GLUTs level seem to facilitate accelerated metabolism, high glucose requirements, and increased glucose uptake in malignant cells. Several factors have been implicated in the regulation of their expressions. Hormonal, for example, ovarian hormones, particularly estrogen, could provide a mechanism of GLUT regulation [30]. In addition, hypoxic also drives GLUT expression [31] as well as metabolic-stress-induced signaling pathways, such as adenosine monophosphateactivated protein kinase (AMPK), triggering upregulation of GLUT receptors [32].

MiRNAs could regulate glucose uptake via altering the GLUTs expressions. MiR-133 has been confirmed to regulate the expression of GLUT4 by targeting KLF15 in a rat model [31]. A study in renal cell carcinoma demonstrated that down-regulated miR-199a, miR-138, miR-150 and miR-532-5p were correlated with an increased expression of GLUT-1, whereas an increased expression of miR-130b, miR-19a, miR-19b and miR-301a can result in the down-regulation of GLUT-1 [32]. MiR-195-5p has been identified as a direct regulator of GLUT3 by targeting GLUT3 3'-untranslated region in bladder cancer T24 cells [33]. Interestingly, miR-19a and miR-133a are altered in colorectal carcinoma [34], and their roles in regulating GLUT expression might explain the disordered metabolism in colorectal carcinoma. In addition, miR-130b is highly down-regulated in pancreatic tumors, and its role in regulating GLUT-1 expression might explain the increased glucose uptake in pancreatic adenocarcinoma [35].

\section{Functions of miRNAs on glycolysis}

Studies show that miRNAs regulate the irreversible steps in glycolysis, especially the key enzymes [33]. For example, miR-143, as an essential regulator of glycolysis, modulates glycolysis via targeting HK2 [12], which phosphorylates glucose to produce glucose 6-phosphate, thus committing glucose to the glycolytic pathway. Recently new protein targets of miRNAs have been identified by sensitive mass spectrometric studies. The oxysterol-binding-proteinrelated-protein 8 has been revealed as a target of miR-143 by quantitative mass spectrometry analysis [34]. For example, miR-155 could repress miR-143 thereby upregulating the expression of HK2 at the post-transcriptional level, except by activating the signal transducer and activator of transcription 3, a transcriptional activator for HK2 [35]. Besides, miR-143 inhibits the expression of HK2 both in primary keratinocytes and in head and neck squamous cell carcinoma-derived cell lines [36]. What's more, HK2 has been validated as a miR-143 target and thus miR-143 could affect glucose metabolism in colon cancer cells [37]. Likewise, miR-143 has also been identified as an essential regulator of cancer glycolysis via targeting HK2 in human lung cancer [12]. Interestingly, the above articles were published almost at the same time. These reports all illustrated that miR-143 targets HK2 to regulate glucose metabolism in cancer cells, and it is a potential cancer therapeutic target.

Except for targeting the irreversible rate-limiting steps, miRNAs also regulate other important intermediate steps in the glycolysis pathway. The enzyme Aldo A catalyzes a reversible aldol reaction in which fructose 1,6bisphosphate is broken down into glyceraldehyde 3phosphate and dihydroxyacetone phosphate. In this process, miR-122 was predicted to target Aldo A [26,38], and the miR-15a/16-1 cluster could reduce the levels of Aldo A [27]. Thus miR-122 and miR-15a/16-1 cluster are involved in glycolysis in cancer cells. 


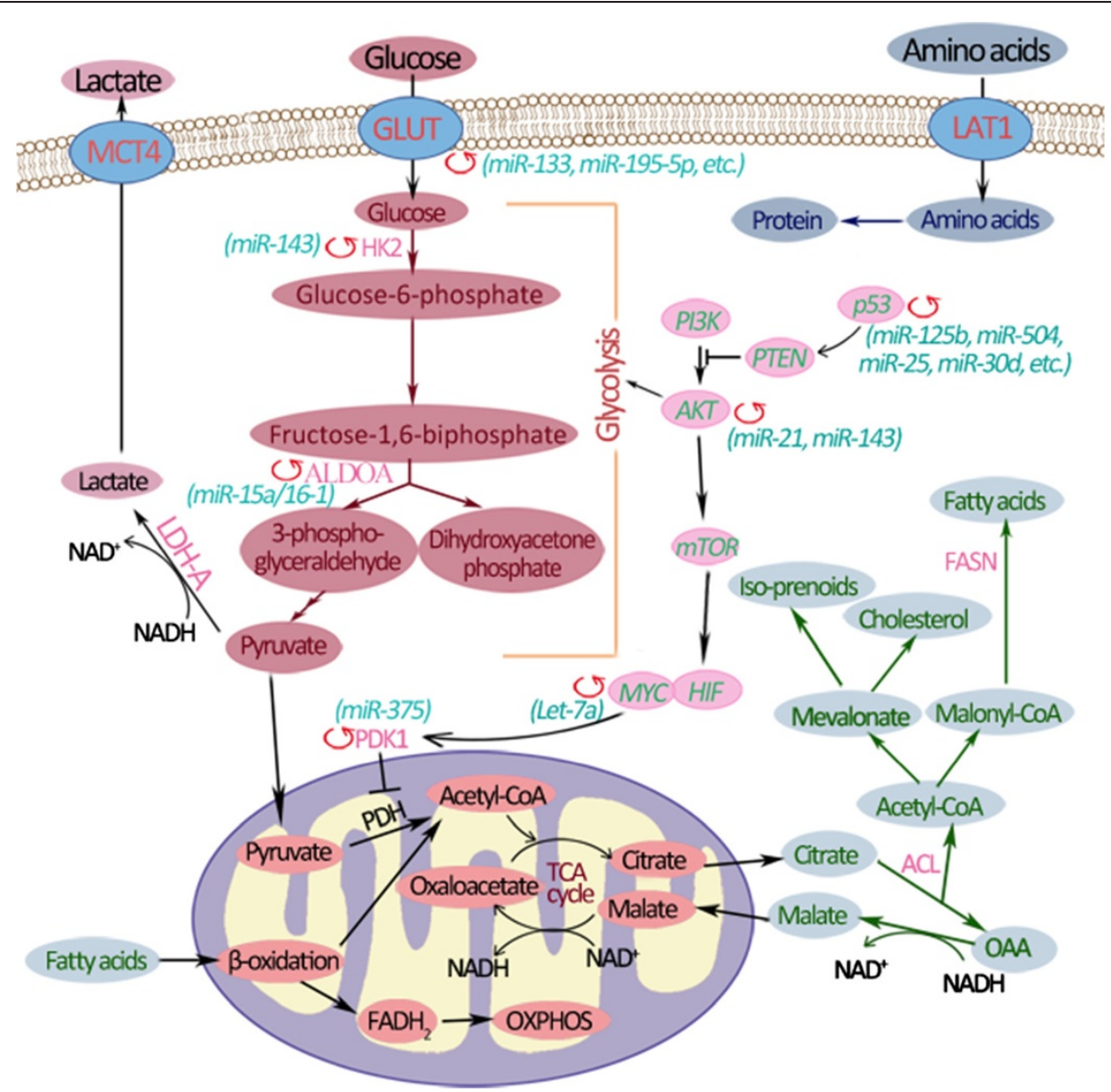

Figure 3 MicroRNAs regulate cell metabolism by targeting key metabolic enzymes and multiple oncogenic signaling pathways. MiRNAs could regulate cell metabolism by modulating the expression of metabolic transporters (like GLUT) or enzymes (HK2, ALDOA and PDK1) and acting on p53, c-Myc and AKT/mTOR signaling pathways. The steps regulated by miRNAs are indicated by red circular arrows, and the related miRNAs are listed in the bracket. FASN, fatty acid synthase; GLUT, glucose transporter; HIF, hypoxia-inducible factor; LAT1, L-type amino acid transporter 1; LDH-A, lactate dehydrogenase isoform A; MCT, monocarboxylate transporter; PDH, pyruvate dehydrogenase; PDK, pyruvate dehydrogenase kinase; PI3K, phosphatidylinositol 3-kinase.

\section{Roles of miRNAs in TCA cycle}

As described before, aerobic glycolysis in tumor cells implies conversion of glucose into pyruvate and subsequently into lactic acid [39]. Acetyl-CoA tends to be introduced into a truncated TCA cycle, with the net result that acetyl-CoA is exported into cytosol. In this truncated TCA cycle, citrate is preferentially exported to cytosol and cleaved by ATP citrate lyase (ACL) to generate oxaloacetate and acetyl-CoA. Oxaloacetate is reduced to malate, then reimported into mitochondria and reconverted to oxaloacetate in the matrix (while generating $\mathrm{NADH}$ that represses the TCA cycle), and it reacts with acetyl-CoA to complete the substrate cycle.

A shift in glucose metabolism from oxidative phosphorylation to aerobic glycolysis has been accepted as a common event in cancer. This process implicates different kinds of energy production pathways are mediated by diverse regulators, including miRNAs [40]. For example, miR-103 and miR-107 have been predicted in regulating acetyl $\mathrm{CoA}$ and lipid levels in cellular systems [41]. Additionally, a set of miRNAs, including miR-152, miR-148a, miR-148b, miR-299-5p, miR-19b, miR-122a, miR-421, miR-494 and miR-19a [23], regulate the citrate synthase gene which encodes a major enzyme in TCA cycle. Besides, miR-210, a miRNA specifically induced by HIF- $1 \alpha$ during hypoxia, represses the iron-sulfur cluster assembly proteins (ISCU1/2) [42]. ISCU1/2 facilitates the assembly of [4Fe-4S] and [2Fe-2S] iron-sulfur clusters, which are incorporated into the TCA cycle related enzymes, like aconitase. Thereby, the effect of miR-210 on ISCU1/2 leads to decrease the activity of TCA cycle. Furthermore, miRNAs also regulate TCA cycle indirectly by acting on transcription factors Myc and HIF etc. 


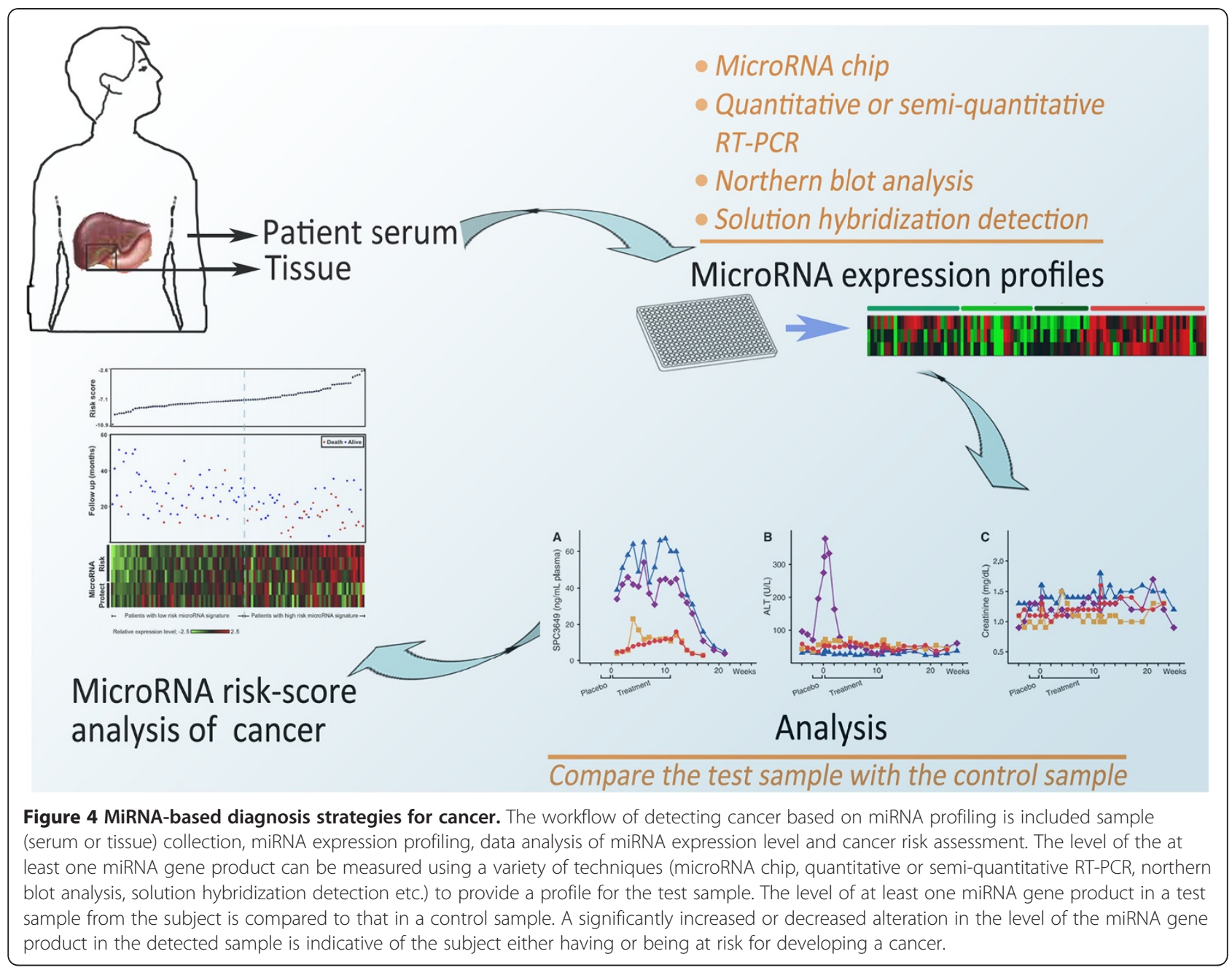

\section{Regulation of insulin production by miRNAs}

MiRNAs have shown to modulate the secretion, action and sensitivity of insulin to affect glucose uptake and production [43]. Insulin acts in concerting with glucagon to maintain glucose homeostasis. MiR-375 has been identified to be expressed selectively in pancreatic endocrine cell lines. The overexpression of miR-375 results in suppressed glucose-stimulated insulin secretion and its inhibition enhances insulin secretion [44]. Besides, Myotrophin, a protein implicated in exocytosis, was a validated target of miR-375. Similarly, a tantalizing new candidate target of miR-375, 3'-phosphoinositidedependent protein kinase-1, is a key molecule in PI3kinase signaling in pancreatic $\beta$-cells [45].

\section{MiRNAs affect lipid metabolism}

Several miRNAs participate in the regulation of lipid metabolism. The deletion of miR-14 increased the levels of triacylglycerol and diacylglycerol while its overexpression resulted in the converse effect, suggesting that miR-14 acts as a regulator of fat metabolism [46].
Additionally, there's evidence that miRNAs are involved in the development and maturation of adipocytes from precursor cells called pre-adipocytes [47,48]. MiR-122 could act as an important regulator of cholesterol and fatty-acid metabolism in the adult liver [49]. The inhibition of miR-122 in normal mice resulted in reduced plasma cholesterol levels, increased hepatic fatty-acid oxidation, and a decrease in hepatic fatty-acid and cholesterol synthesis rates, but resulted in decreased plasma cholesterol levels, a significant improvement in liver steatosis and reductions in several lipogenic genes. After that, miR-122 has been found as an important regulator in liver lipid metabolism [50]. In the recent article, miR-27a has been revealed to be involved in adipocyte differentiation by binding to the PPAR $\gamma$ 3'-UTR, whose sequence motifs are highly conserved in mammals [51]. All these studies indicate that miRNA plays an important role in lipid metabolism.

The changes of miRNA expression in $\beta$-cell under physiopathological conditions have been illustrated before. And at least part of the detrimental effects of 
palmitate on pancreatic $\beta$-cells has been caused by alteration in the levels of specific miRNAs, like miR-34a and miR-146 [52]. Apart from that, the up-regulation of miR-335 has also been found in obesity by microarray analysis [53]. Besides, the expression of miR-335 was upregulated in liver and white adipose tissue in obese mice, which was associated with an elevated body, liver and WAT weight, and hepatic triglyceride and cholesterol. Additionally, miR-370 acting via miR-122 may accumulate hepatic triglycerides by modulating initially the expression of SREBP-1c, DGAT2, and Cpt1 $\alpha$ and, subsequently, the expression of other genes that affect lipid metabolism [54].

Recently, miR-33a/b has been discovered to govern cholesterol / lipid metabolism and energy homeostasis [55]. MiR-33a/b embeds within intron sequences of the human SREBF genes and controls the levels of ATPbinding cassette transporter ABCA1, a cholesterol efflux pump critical for high-density lipoprotein synthesis and reversing cholesterol transport from peripheral tissues [56,57]. MiR-33a/b also acts in the lipid homeostasis pathway by controlling the expression of fatty acid $\beta$-oxidation genes including carnitine $O$-octanoyltransferase, hydroxyacyl-CoA-dehydrogenase, and carnitine palmitoyltransferase $1 \mathrm{~A}$, as well as energy homeostasis regulators AMPK a1, SIRT6, and insulin receptor substrate 2 [58]. These reports bring us a further view of miRNA function on lipid metabolism.

\section{Effects of miRNA in amino acid metabolism}

Amino acid metabolism is linked to biosynthesis of protein, nucleotide and lipids, redox homeostasis, and energy metabolism. MiR-23b* (expressed from the 3'-arm) mediates proline oxidase, the first enzyme in proline catabolism, down-regulation in human kidney tumors [59]. Furthermore, the metabolic link between proline and glutamine afforded by Myc emphasizes the complexity of tumor metabolism. While miR-122 was reported to downregulate the high affinity cationic amino acid transporter CAT-1 [60], thereby regulating amino acid metabolism. Involving evidences have been found in Drosophila, where miR-277 plays a role as a metabolic switch controlling amino acid catabolism by bioinformatics approaches [61]. Additionally, miR29b has been identified to control the component of the branched chain a-ketoacid dehydrogenase complex, which catalyzes the irreversible step in branched chain amino acids (including leucine, isoleucine and valine) catabolism [62], suggesting that miR-29b exerts effects of controlling on amino acid catabolism.

miRNA regulation of signaling pathways in cell metabolism The intertwined connections between aberrant expression of microRNAs and unbalanced signaling pathways contribute to abnormal cell metabolism and carcinogenesis. The specific p53, c-Myc, AMPK and AKT signaling pathways are included to clarify their roles in miRNAmediated metabolism.

\section{p53 pathway}

$\mathrm{p} 53$, one of the most common tumour suppressor genes, functions to prevent tumour development by inhibiting the outgrowth of stressed or damaged cells. In addition to well established functions to block cell proliferation, recent studies have revealed regulation roles for p53 involved in metabolism [63]. The p53 can inhibit the expression of GLUT-1, GLUT-4, phosphoglyceromutase and TIGAR to affect glycolysis. TIGAR is TP53-induced glycolysis and apoptosis regulator protein, and it inhibits the glycolytic enzyme PFKFB2 [64]. Additonally, p53 could also activate the expression of synthesis of cytochrome c oxidase 2 at transcriptional level [65] and induce the expression of the ribonucleotide reductase subunit p53R2 [66], leading to the restraint on glycolytic rate.

Several miRNAs are able to control p53 activity. The miR-125b has been identified as a negative regulator of p53 in both zebrafish and human [67]. To date, miRNAs including miR-125b, miR-504, miR-25, miR-30d, miR-34a, miR-122, miR-29, miR-192, miR-194 and miR-215 have been shown to regulate p53 abundance and/or activity. Among these, miR-125b, miR-504, miR-25 and miR-30d negatively regulate $\mathrm{p} 53$ by binding to its 3 'UTR whereas the others indirectly influence p53 abundance and/or activity by regulating the regulators of p53 [68]. The functions of these miRNAs on p53 give a clue of their effects in cancer cell metabolism.

\section{c-Myc pathway}

The c-Myc is a transcription factor that regulates the expression of genes involved in nucleotide metabolism, DNA replication, and ribosomal and mitochondrial biogenesis. Studies in the past few years have led to the identification of miRNAs as novel regulators of c-Myc activity. A mutated version of Myc leads to the unregulated expression of many genes, some of which are involved in cell proliferation and results in the formation of cancer [69]. For example, c-Myc has crucial roles in glutamine metabolism mediated by miR-23b [70]. Moreover, in concerts with HIF1 to regulate glucose uptake and glycolytic enzyme expression, thus favouring tumour growth in hostile environments [71].

The regulation of Myc mRNA by let-7a has been confirmed [72]. Similiarly, the overexpression of let-7a can inhibit the growth of lung cancer transplanted subcutaneously in nude mice by suppression of k-Ras and cMyc [73]. Inspiringly, c-Myc transcriptionally represses miR-23a and miR-23b, resulting in increased expression 
of mitochondrial glutaminase, enhancing glutamine catabolism through increased mitochondrial glutaminase expression [6].

\section{AMPK pathway}

AMPK acts as a metabolic master switch regulating several intracellular systems including the cellular uptake of glucose, the $\beta$-oxidation of fatty acids and the biogenesis of GLUT4 and mitochondria [74]. AMPK controls glucose homeostasis by regulating metabolism in multiple peripheral tissues, such as skeletal muscle, liver, adipose tissues, and pancreatic $\beta$ cells [75].

The functions of miR-375 on glucose homeostasis have been studied [76]. Total 381 putative direct targets of miR-375 were selected, which contained a miR-375 recognition motif, and confirmed 10 of these genes, involving caveolin1 [77,78], inhibitor of DNA binding 3 [79,80], Smarca2, Ras-dexamethasone-induced-1 [81], regulator of G protein signaling 16 [82], eukaryotic elongation factor 1 epsilon 1, apoptosis-inducing factor, mitochondrion-associated 1 , cell adhesion molecule 1 , $\mathrm{HuD}$ antigen [83], and complement component $1 \mathrm{q}$ subcomponent binding protein. Published data have shown that some of these genes play a role in AMPK signaling, inducing apoptosis and inhibiting normal developmental growth processes or the proliferation of tumors.

\section{AKT pathway}

The PI3K/AKT/mTOR pathway is an intracellular signalling pathway, which is important in apoptosis. It has risen to prominence as a key regulator of cell cycle proliferation, growth, survival, protein synthesis, and glucose metabolism [84]. Activation of PI3K leads to the activation of downstream effectors including Akt and mTOR that support cellular biosynthesis [85-87]. Enhanced PI3K/Akt signal increases the expression of nutrient transporters, enabling increased uptake of glucose, amino acids, and other nutrients. Additionally, Akt-dependent stimulation of hexokinase and phosphofructokinase drives glycolysis. Furthermore, AKT-involved signaling enhances transcription of genes to involve in glycolysis and lipid genesis [88-90].

Regulation of this pathway by miRNAs mainly results in altered glucose and lipid metabolism. For example, miR-21, which inhibits a negative regulator PTEN of the PIK/AKT pathway, is induced in gemcitabine-resistant pancreatic cancer cells [28]. And AKT pathway can involve in glycolysis by directly regulating glycolytic enzymes and activating downstream mTOR activity. Similiarly, ORP8 has been identied as an miR-143 target and the reduction of ORP8 expression in cultured liver cells impairs the ability of insulin to induce AKT activation, revealing an ORP8-dependent mechanism of AKT regulation [91].

\section{MiRNAs affect multiple targets in regulatory networks}

Certain miRNAs have also been shown to affect multiple targets in linear pathways or interconnected nodes in regulatory networks [25], thereby exerting a larger cumulative effect $[9,55]$. For example, miR-33a and miR$33 \mathrm{~b}$, as described before, interact with the SREBP transcription factors to regulate cholesterol and lipid homeostasis. Furthermore, they may also influence insulin signaling and glucose regulation by targeting IRS2, SIRT6 and AMPK $\alpha 1$ [58]. MiR-34a, a miRNA that may have important function in a network with SIRT1 and p53, has additionally been implicated in cholesterol, lipid and energy homeostasis [52,68]. MiRNAs typically have rather modest effects on target protein levels, and combinatorial actions on multiple functionally related targets are probably required for single miRNAs to significantly influence a complex biological process such as metabolic homeostasis.

\section{MiRNAs as biomarkers for human cancer}

By targeting and controlling the expression of mRNA, miRNAs can control highly complex signal transduction pathways and multiple metabolic processes, which are usually involved in different oncogenic pathways [92]. The knowledge that miRNA expression is frequently dysregulated in cancer has uncovered an entirely new repertoire of molecular factors upstream of gene expression, with exciting potential as novel biomarkers and therapeutic targets in cancer [93]. Exploiting the unique characteristics of these molecules including their stability, tissue specificity, ease of detection and manipulation, will bring clinicians ever closer to achieving the goal of individualized cancer treatment [94].

On the one hand, miRNAs are produced in a tissuespecific manner, and changes in miRNA within a tissue type can be correlated with disease status. The tissue concentrations of specific miRNAs have been associated with tumor invasiveness, metastatic potential, and other clinical characteristics for several types of cancers, including chronic lymphocytic leukemia, and breast, colorectal, hepatic, lung, pancreatic, and prostate cancers [95]. On the other hand, there has been an accumulating body of evidence to support circulating miRNAs as noninvasive, sensitive biomarkers of disease states, particularly cancers (breast, lung, pancreas, ovarian, and prostate) [96]. For example, miR-9 and miR-9* (expressed from the 3' mature sequence), mostly neuronal and thus expressed in central nervous system tumors but absent in other tumors, present their potential as tumor markers [97]. In addition, the reduced levels of miR-126, members of the miR-17-92 cluster, inflammation-related miR-155, and smooth muscle-enriched miR-145 in patients with coronary artery disease compared with healthy controls [98]. What's more, published data 
showed that plasma miR-29a and miR-92a have strong potential as novel noninvasive biomarkers for early detection of colorectal carcinoma [99].

Furthermore, since they are abundant in blood, easy to measure, highly stable and disease associated, serum microRNAs are attractive disease biomarkers [100]. There have been over 200 publications on circulating miRNA in cancers including prostate, breast, colon, lung, ovarian and leukemia since 2008. Considering the sources of variation, state of microRNA in plasma and origin and implications for disease specificity, miRNA expression profiles of potential patients could be assessed by measuring circulating miRNAs in patient serum. This profile could be hopefully used for early detection of cancer.

\section{Conclusion and perspective}

MiRNAs are important regulators of numerous aspects of metabolic homeostasis, physiology and disease. In general, miRNAs could mainly have two ways to regulate cellular metabolism. MiRNAs could regulate transcription factors or signaling proteins, which in turn regulate metabolic enzymes. Alternatively, miRNAs could regulate the production of certain metabolites by directly regulating the genes that encode metabolic enzymes [101]. In addition, miRNAs could regulate mRNAs through chromatin remodeling [102]. The emergence of miRNAs as important regulators of metabolism has garnered much interest not only from a scientific point of view but also from a clinical perspective. The function of miRNAs on cellular metabolism reveals molecular strategies for controlling metabolic flux by miRNAs in living organisms, thus lighting up one aspect of miRNA therapeutics. MiRNAs are promising in the diagnosis of cancer, drug target identification and clinical treatment in the future (Figure 4). The use of miRNAs, such as oligonucleotide complementary [103] or antisense oligonucleotides [104] in miRNA inhibition, to suppress cell metabolism altering will hopefully lead to a new therapeutic strategy for malignant cancer $[105,106]$. For example, endothelial miR-126 is deregulated in patients with type 2 diabetes, which may ultimately lead to novel biomarkers for risk estimation and classification and could be exploited for miRNA-based therapeutic interventions of vascular complications associated with this disease [107].

So far, a variety of new strategies to identify and characterize the targets of individual miRNAs have been developed. Because miRNAs can also regulate other non-coding RNAs, these interactions will increase the complexity of gene regulation. Moreover, cost-effective miRNA profiling strategies and larger studies are needed to determine its advantage for cancer diagnosis. Additionally, a new class of miRNA-based drugs that are capable of targeting molecules outside the range of traditional medicinal chemistry, their clinical implementation will require improvements in drug composition and delivery. Since these challenges lie on the way, molecular strategies for cancer therapy by miRNAs are still in their infancy. Nevertheless, the successful development of miRNA biology technologies could ultimately translate our understanding of miRNA functions in cancer into strategies for the control of cancer.

\begin{abstract}
Abbreviations
ACL: ATP citrate lyase; AldoA: Aldolase A; AMPK: Adenosine monophosphateactivated protein kinase; GLUT: Glucose transporter; ISCU1/2: Iron-sulfur cluster assembly proteins; HIF1: Hypoxia-inducible factor 1; HK2: Hexokinase 2; MiRNA: MicroRNA; MTOR: Mammalian target of rapamycin; ORP: Oxysterolbinding-protein-related-protein; RISC: RNA-induced silenced complex; TCA: Tricarboxylic acid.
\end{abstract}

\section{Competing interests}

The authors declare that they have no competing interests.

\section{Authors' contributions}

All authors participated in the preparation of the manuscript, read and approved the final manuscript.

\section{Acknowledgements}

This work was financially supported by the grants from National Key Basic Research Program of China (2011CB910703, 2013CB911303), National Natural Sciences Foundation of China (30970654, 31071235), and grants for New Century Excellent Talents in University (NCET-10-0595), specialized research fund for the Doctoral Program of Higher Education (20120181110025). This research was also funded by Sichuan Province Program (2010JQ0016, 2012SZ0002) and Chengdu Local Scientific Project (11DXYB356JH-027).

\section{Author details}

${ }^{1}$ State Key Laboratory of Biotherapy, West China Hospital, Sichuan University, No.17, third section of Renmin South Road, Chengdu 610041, People's Republic China. 'Department of Gynecology and Obstetrics, West China Second Hospital, Sichuan University, Chengdu 610041, People's Republic China.

Received: 27 September 2012 Accepted: 16 November 2012 Published: 20 November 2012

\section{Reference}

1. Kutter C, Svoboda P: miRNA, siRNA, piRNA. RNA Biol 2008, 5:181-188.

2. Lewis BP, Burge CB, Bartel DP: Conserved seed pairing, often flanked by adenosines, indicates that thousands of human genes are microRNA targets. Cell 2005, 120:15-20.

3. Bartel DP: MicroRNAs: genomics, biogenesis, mechanism, and function. Cell 2004, 116:281-297.

4. Krutzfeldt J, Stoffel M: MicroRNAs: a new class of regulatory genes affecting metabolism. Cell Metab 2006, 4:9-12.

5. Redova M, Svoboda M, Slaby O: MicroRNAs and their target gene networks in renal cell carcinoma. Biochem Biophys Res Commun 2011, 405:153-156.

6. Gao P, Tchernyshyov I, Chang TC, Lee YS, Kita K, Ochi T, Zeller KI, De Marzo AM, Van Eyk JE, Mendell JT, Dang CV: c-Myc suppression of miR-23a/b enhances mitochondrial glutaminase expression and glutamine metabolism. Nature 2009, 458:762-765.

7. Rayner KJ, Suarez Y, Davalos A, Parathath S, Fitzgerald ML, Tamehiro N, Fisher EA, Moore KJ, Fernandez-Hernando C: MiR-33 contributes to the regulation of cholesterol homeostasis. Science 2010, 328:1570-1573.

8. Eichner $\amalg$, Perry M-C, Dufour CR, Bertos N, Park M, St-Pierre J, Giguère V: miR-378* mediates metabolic shift in breast cancer cells via the PGC1及/ERRy transcriptional pathway. Cell Metab 2010, 12:352-361.

9. Rottiers $\mathrm{V}$, Naar AM: MicroRNAs in metabolism and metabolic disorders. Nat Rev Mol Cell Biol 2012, 13:239-250. 
10. Pucci S, Mazzarelli P: MicroRNA dysregulation in colon cancer microenvironment interactions: the importance of small things in metastases. Cancer Microenviron 2011, 4:155-162.

11. Cairns RA, Harris IS, Mak TW: Regulation of cancer cell metabolism. Nat Rev Cancer 2011, 11:85-95.

12. Fang R, Xiao T, Fang Z, Sun Y, Li F, Gao Y, Feng Y, Li L, Wang Y, Liu X, et al: miR-143 regulates cancer glycolysis via targeting hexokinase 2 . J Biol Chem 2012, 287:23227-23235.

13. Lagos-Quintana M, Rauhut R, Lendeckel W, Tuschl T: Identification of novel genes coding for small expressed RNAs. SCi STKE 2001, 294:853.

14. Lee RC, Ambros V: An extensive class of small RNAs in Caenorhabditis elegans. Science 2001, 294:862-864

15. He L, Hannon GJ: MicroRNAs: small RNAs with a big role in gene regulation. Nat Rev Genet 2004, 5:522-531.

16. Winter J, Jung S, Keller S, Gregory Rl, Diederichs S: Many roads to maturity: microRNA biogenesis pathways and their regulation. Nat Cell Biol 2009, 11:228-234.

17. Carthew RW, Sontheimer EJ: Origins and mechanisms of miRNAs and siRNAs. Cell 2009, 136:642-655.

18. Hanahan D, Weinberg RA: Hallmarks of cancer: the next generation. Cell 2011, 144:646-674.

19. Hsu PP, Sabatini DM: Cancer cell metabolism: Warburg and beyond. Cell 2008, 134:703-707.

20. Kroemer G, Pouyssegur J: Tumor cell metabolism: cancer's Achilles' heel. Cancer Cell 2008, 13:472-482.

21. Vander Heiden MG, Locasale JW, Swanson KD, Sharfi H, Heffron GJ, AmadorNoguez D, Christofk HR, Wagner G, Rabinowitz JD, Asara JM, Cantley LC Evidence for an alternative glycolytic pathway in rapidly proliferating cells. Science 2010, 329:1492-1499.

22. Jones RG, Thompson CB: Tumor suppressors and cell metabolism: a recipe for cancer growth. Gene Dev 2009, 23:537-548.

23. Tibiche $C$, Wang E: MicroRNA regulatory patterns on the human metabolic network. Open Syst Biol J 2008, 1:1-8.

24. Horie T, Ono K, Nishi H, Iwanaga Y, Nagao K, Kinoshita M, Kuwabara Y, Takanabe R, Hasegawa K, Kita T: MicroRNA-133 regulates the expression of GLUT4 by targeting KLF15 and is involved in metabolic control in cardiac myocytes. Biochem Biophys Res Commun 2009, 389:315-320.

25. Fei $X$, Qi M, Wu B, Song Y, Wang Y, Li T: MicroRNA-195-5p suppresses glucose uptake and proliferation of human bladder cancer T24 cells by regulating GLUT3 expression. FEBS Lett 2012, 586:392-397.

26. Coulouarn C, Factor VM, Andersen JB, Durkin ME, Thorgeirsson SS: Loss of miR122 expression in liver cancer correlates with suppression of the hepatic phenotype and gain of metastatic properties. Oncogene 2009, 28:3526-3536.

27. Calin GA, Cimmino A, Fabbri M, Ferracin M, Wojcik SE, Shimizu M, Taccioli C, Zanesi N, Garzon R, Ageilan Rl, et al: MiR-15a and miR-16-1 cluster functions in human leukemia. Proc Natl Acad Sci USA 2008, 105:5166-5171.

28. Ali S, Ahmad A, Banerjee S, Padhye S, Dominiak K, Schaffert JM, Wang Z, Philip PA, Sarkar FH: Gemcitabine sensitivity can be induced in pancreatic cancer cells through modulation of miR-200 and miR-21 expression by curcumin or its analogue CDF. Cancer Res 2010, 70:3606-3617.

29. Thorens B, Mueckler M: Glucose transporters in the 21 st century. Am J Physiol Endocrinol Metab 2010, 298:E141-E145.

30. Rivenzon-Segal D, Boldin-Adamsky S, Seger D, Seger R, Degani H: Glycolysis and glucose transporter 1 as markers of response to hormonal therapy in breast cancer. Int J Cancer 2003, 107:177-182.

31. Macheda ML, Rogers S, Best JD: Molecular and cellular regulation of glucose transporter (GLUT) proteins in cancer. J Cell Physiol 2005, 202:654-662.

32. Koh HJ, Toyoda T, Fujii N, Jung MM, Rathod A, Middelbeek RJ, Lessard SJ, Treebak JT, Tsuchihara K, Esumi H, et al: Sucrose nonfermenting AMPKrelated kinase (SNARK) mediates contraction-stimulated glucose transport in mouse skeletal muscle. Proc Natl Acad Sci USA 2010, 107:15541-15546

33. Singh PK, Mehla K, Hollingsworth MA, Johnson KR: Regulation of aerobic glycolysis by microRNAs in cancer. Mol Cell Pharmacol 2011, 3:125-134.

34. Kruger M, Moser M, Ussar S, Thievessen I, Luber CA, Forner F, Schmidt S, Zanivan S, Fassler R, Mann M: SILAC mouse for quantitative proteomics uncovers kindlin-3 as an essential factor for red blood cell function. Cell 2008, 134:353-364.

35. Jiang S, Zhang LF, Zhang HW, Hu S, Lu MH, Liang S, Li B, Li Y, Li D, Wang ED, Liu MF: A novel miR-155/miR-143 cascade controls glycolysis by regulating hexokinase 2 in breast cancer cells. EMBO J 2012, 31:1985-1998.
36. Peschiaroli A, Giacobbe A, Formosa A, Markert EK, Bongiorno-Borbone L, Levine AJ, Candi E, D'Alessandro A, Zolla L, Finazzi Agro A, Melino G: miR143 regulates hexokinase 2 expression in cancer cells. Oncogene 2012, doi:10.1038/onc.2012.100.

37. Gregersen LH, Jacobsen A, Frankel LB, Wen J, Krogh A, Lund AH: microRNA-143 down-regulates Hexokinase 2 in colon cancer cells. BMC Cancer 2012, 12:232.

38. Tsai WC, Hsu PW, Lai TC, Chau GY, Lin CW, Chen CM, Lin CD, Liao YL, Wang $J$, Chau YP, et al: MicroRNA-122, a tumor suppressor microRNA that regulates intrahepatic metastasis of hepatocellular carcinoma. Hepatology 2009, 49:1571-1582

39. Ward PS, Thompson CB: Metabolic reprogramming: a cancer hallmark even warburg did not anticipate. Cancer Cell 2012, 21:297-308.

40. Singh PK, Brand RE, Mehla K: MicroRNAs in pancreatic cancer metabolism. Nat Rev Gastro Hepat 2012, 9:334-344.

41. Wilfred BR, Wang WX, Nelson PT: Energizing miRNA research: a review of the role of miRNAs in lipid metabolism, with a prediction that miR103/107 regulates human metabolic pathways. Mol Genet Metab 2007, 91:209-217

42. Chan SY, Zhang YY, Hemann C, Mahoney CE, Zweier JL, Loscalzo J: MicroRNA-210 controls mitochondrial metabolism during hypoxia by repressing the iron-sulfur cluster assembly proteins ISCU1/2. Cell Metab 2009, 10:273-284.

43. Trajkovski M, Hausser J, Soutschek J, Bhat B, Akin A, Zavolan M, Heim MH, Stoffel M: MicroRNAs 103 and 107 regulate insulin sensitivity. Nature 2011, 474:649-653.

44. Poy MN, Eliasson L, Krutzfeldt J, Kuwajima S, Ma X, MacDonald PE, Pfeffer S, Tuschl T, Rajewsky N, Rorsman P: A pancreatic islet-specific microRNA regulates insulin secretion. Nature 2004, 432:226-230.

45. El Ouaamari A, Baroukh N, Martens GA, Lebrun P, Pipeleers D, van Obberghen E: miR-375 targets 3'-phosphoinositide-dependent protein kinase- 1 and regulates glucose-induced biological responses in pancreatic beta-cells. Diabetes 2008, 57:2708-2717.

46. Xu P, Vernooy SY, Guo M, Hay BA: The Drosophila microRNA Mir-14 suppresses cell death and is required for normal fat metabolism. Curr Biol 2003, 13:790-795.

47. Esau C, Kang X, Peralta E, Hanson E, Marcusson EG, Ravichandran LV, Sun Y, Koo S, Perera RJ, Jain R, et al: MicroRNA-143 regulates adipocyte differentiation. J Biol Chem 2004, 279:52361-52365.

48. Kajimoto K, Naraba H, Iwai N: MicroRNA and 3T3-L1 pre-adipocyte differentiation. RNA 2006, 12:1626-1632.

49. Esau C, Davis S, Murray SF, Yu XX, Pandey SK, Pear M, Watts L, Booten SL, Graham M, McKay R, et al: miR-122 regulation of lipid metabolism revealed by in vivo antisense targeting. Cell Metab 2006, 3:87-98.

50. Lynn FC: Meta-regulation: microRNA regulation of glucose and lipid metabolism. Trends Endocrinol Metab 2009, 20:452-459.

51. Kim SY, Kim AY, Lee HW, Son YH, Lee GY, Lee JW, Lee YS, Kim JB miR-27a is a negative regulator of adipocyte differentiation via suppressing PPARgamma expression. Biochem Biophys Res Commun 2010, 392:323-328.

52. Lovis P, Roggli E, Laybutt DR, Gattesco S, Yang JY, Widmann C, Abderrahmani A, Regazzi R: Alterations in microRNA expression contribute to fatty acid-induced pancreatic beta-cell dysfunction. Diabetes 2008, 57:2728-2736.

53. Nakanishi N, Nakagawa Y, Tokushige N, Aoki N, Matsuzaka T, Ishii K, Yahagi N, Kobayashi K, Yatoh S, Takahashi A, et al: The up-regulation of microRNA-335 is associated with lipid metabolism in liver and white adipose tissue of genetically obese mice. Biochem Biophys Res Commun 2009, 385:492-496.

54. Iliopoulos D, Drosatos K, Hiyama Y, Goldberg IJ, Zannis VI: MicroRNA-370 controls the expression of MicroRNA-122 and Cpt1 and affects lipid metabolism. J Lipid Res 2010, 51:1513-1523.

55. Rottiers V, Najafi-Shoushtari SH, Kristo F, Gurumurthy S, Zhong L, Li Y, Cohen DE, Gerszten RE, Bardeesy N, Mostoslavsky R, Naar AM: MicroRNAs in metabolism and metabolic diseases. Cold Spring Harb Symp Quant Biol 2011, 76:225-233.

56. Najafi-Shoushtari SH, Kristo F, Li Y, Shioda T, Cohen DE, Gerszten RE, Naar AM: MicroRNA-33 and the SREBP host genes cooperate to control cholesterol homeostasis. Sci Signalling 2010, 328:1566.

57. Gerin I, Clerbaux LA, Haumont O, Lanthier N, Das AK, Burant CF, Leclercq IA, MacDougald OA, Bommer GT: Expression of miR-33 from an SREBP2 intron inhibits cholesterol export and fatty acid oxidation. J Biol Chem 2010, 285:33652-33661. 
58. Dávalos A, Goedeke L, Smibert P, Ramírez CM, Warrier NP, Andreo U, CireraSalinas D, Rayner K, Suresh U, Pastor-Pareja JC: miR-33a/b contribute to the regulation of fatty acid metabolism and insulin signaling. Proc Natl Acad Sci USA 2011, 108:9232-9237.

59. Liu W, Le A, Hancock C, Lane AN, Dang CV, Fan TW, Phang JM: Reprogramming of proline and glutamine metabolism contributes to the proliferative and metabolic responses regulated by oncogenic transcription factor c-MYC. Proc Natl Acad Sci USA 2012, 109:8983-8988.

60. Chang J, Nicolas E, Marks D, Sander C, Lerro A, Buendia MA, Xu C, Mason WS, Moloshok T, Bort R: Research Paper miR-122, a Mammalian Liver-Specific microRNA, is Processed from mRNA and May Downregulate the High Affinity Cationic Amino Acid Transporter CAT-1. RNA Biol 2004, 1:106-113.

61. Stark A, Brennecke J, Russell RB, Cohen SM: Identification of Drosophila MicroRNA targets. PLoS Biol 2003, 1:E60

62. Mersey BD, Jin P, Danner DJ: Human microRNA (miR29b) expression controls the amount of branched chain alpha-ketoacid dehydrogenase complex in a cell. Hum Mol Genet 2005, 14:3371-3377.

63. Cheung EC, Vousden $\mathrm{KH}$ : The role of $\mathrm{p} 53$ in glucose metabolism. Curr Opin Cell Biol 2010, 22:186-191.

64. Vousden KH, Ryan KM: p53 and metabolism. Nat Rev Cancer 2009, 9:691-700.

65. Gottlieb E, Vousden $\mathrm{KH}: \mathrm{p} 53$ regulation of metabolic pathways. Cold Spring Harb Perspect Biol 2010, 2:a001040.

66. Bourdon A, Minai L, Serre V, Jais JP, Sarzi E, Aubert S, Chretien D, de Lonlay $P$, Paquis-Flucklinger $V$, Arakawa $H$, et al: Mutation of RRM2B, encoding p53-controlled ribonucleotide reductase (p53R2), causes severe mitochondrial DNA depletion. Nat gene 2007, 39:776-780.

67. Le MT, Teh C, Shyh-Chang N, Xie H, Zhou B, Korzh V, Lodish HF, Lim B: MicroRNA-125b is a novel negative regulator of p53. Genes Dev 2009, 23:862-876

68. Jones M, Lal A: MicroRNAs, wild-type and mutant p53: more questions than answers. RNA Biol 2012, 9:781-791.

69. Soucek L, Whitfield J, Martins CP, Finch AJ, Murphy DJ, Sodir NM, Karnezis AN, Swigart LB, Nasi S, Evan Gl: Modelling Myc inhibition as a cancer therapy. Nature 2008, 455:679-683.

70. Dang CV, Le A, Gao P: MYC-induced cancer cell energy metabolism and therapeutic opportunities. Clin Cancer Res 2009, 15:6479-6483.

71. Gordan JD, Thompson CB, Simon MC: HIF and C-Myc: sibling rivals for control of cancer cell metabolism and proliferation. Cancer Cell 2007, 12:108-113.

72. Sampson VB, Rong NH, Han J, Yang Q, Aris V, Soteropoulos P, Petrelli NJ, Dunn SP, Krueger LJ: MicroRNA let-7a down-regulates MYC and reverts MYC-induced growth in Burkitt lymphoma cells. Cancer Res 2007, 67:9762-9770

73. He XY, Chen JX, Zhang Z, Li CL, Peng QL, Peng HM: The let-7a microRNA protects from growth of lung carcinoma by suppression of k-Ras and cMyc in nude mice. J Cancer Res Clin Oncol 2010, 136:1023-1028.

74. Ojuka EO: Role of calcium and AMP kinase in the regulation of mitochondrial biogenesis and GLUT4 levels in muscle. Proc Nutr Soc 2004, 63:275-278.

75. Long YC, Zierath JR: AMP-activated protein kinase signaling in metabolic regulation. J Clin Invest 2006, 116:1776-1783.

76. Poy MN, Hausser J, Trajkovski M, Braun M, Collins S, Rorsman P, Zavolan M, Stoffel M: miR-375 maintains normal pancreatic alpha- and beta-cell mass. Proc Natl Acad Sci USA 2009, 106:5813-5818.

77. Galbiati F, Liu J, Capozza F, Frank PG, Zhu L, Pestell RG, Lisanti MP: Caveolin1 expression negatively regulates cell cycle progression by inducing $\mathrm{GO}$ / G1 arrest via a p53/p21WAF1/Cip1-dependent mechanism. Mol Bio/ Cell 2001, 12:2229-2244.

78. Cohen AW, Park DS, Woodman SE, Williams TM, Chandra M, Shirani J, Pereira de Souza A, Kitsis RN, Russell RG, Weiss LM, et al: Caveolin-1 null mice develop cardiac hypertrophy with hyperactivation of p42/44 MAP kinase in cardiac fibroblasts. Am J Physiol Cell Physiol 2003, 284:C457-474.

79. Bain G, Cravatt CB, Loomans C, Alberola-lla J, Hedrick SM, Murre C: Regulation of the helix-loop-helix proteins, E2A and Id3, by the Ras-ERK MAPK cascade. Nat Immunol 2001, 2:165-171.

80. Kim DS, Franklyn JA, Boelaert K, Eggo MC, Watkinson JC, McCabe CJ: Pituitary tumor transforming gene (PTTG) stimulates thyroid cell proliferation via a vascular endothelial growth factor/kinase insert domain receptor/inhibitor of DNA binding-3 autocrine pathway. J Clin Endocrinol Metab 2006, 91:4603-4611.

81. Vaidyanathan G, Cismowski MJ, Wang G, Vincent TS, Brown KD, Lanier SM: The Ras-related protein AGS1/RASD1 suppresses cell growth. Oncogene 2004, 23:5858-5863.
82. Neubig RR, Siderovski DP: Regulators of G-protein signalling as new central nervous system drug targets. Nat Rev Drug Discov 2002, 1:187-197.

83. Akamatsu W, Fujihara H, Mitsuhashi T, Yano M, Shibata S, Hayakawa Y, Okano HJ, Sakakibara S, Takano H, Takano T, et al: The RNA-binding protein $\mathrm{HuD}$ regulates neuronal cell identity and maturation. Proc Natl Acad Sci USA 2005, 102:4625-4630.

84. Yap TA, Garrett MD, Walton MI, Raynaud F, de Bono JS, Workman P: Targeting the PI3K-AKT-mTOR pathway: progress, pitfalls, and promises. Curr Opin Pharmacol 2008, 8:393-412.

85. Samuels Y, Wang Z, Bardelli A, Silliman N, Ptak J, Szabo S, Yan H, Gazdar A, Powell SM, Riggins GJ: High frequency of mutations of the PIK3CA gene in human cancers. Science 2004, 304:554-554

86. Samuels Y, Diaz LA Jr, Schmidt-Kittler O, Cummins JM, Delong L, Cheong I, Rago C, Huso DL, Lengauer C, Kinzler KW, et al: Mutant PIK3CA promotes cell growth and invasion of human cancer cells. Cancer Cell 2005, 7:561-573.

87. Jia S, Liu Z, Zhang S, Liu P, Zhang L, Lee SH, Zhang J, Signoretti S, Loda M, Roberts TM, Zhao JJ: Essential roles of PI(3)K-p110beta in cell growth, metabolism and tumorigenesis. Nature 2008, 454:776-779.

88. Edinger AL, Thompson CB: Akt maintains cell size and survival by increasing mTOR-dependent nutrient uptake. Mol Biol Cell 2002, 13:2276-2288.

89. Bauer DE, Harris MH, Plas DR, Lum JJ, Hammerman PS, Rathmell JC, Riley JL, Thompson CB: Cytokine stimulation of aerobic glycolysis in hematopoietic cells exceeds proliferative demand. FASEB J 2004, 18:1303-1305.

90. Wullschleger $\mathrm{S}$, Loewith $\mathrm{R}$, Hall MN: TOR signaling in growth and metabolism. Cell 2006, 124:471-484.

91. Jordan SD, Krüger M, Willmes DM, Redemann N, Wunderlich FT, Brönneke HS, Merkwirth C, Kashkar H, Olkkonen VM, Böttger T, et al: Obesity-induced overexpression of miRNA-143 inhibits insulin-stimulated AKT activation and impairs glucose metabolism. Nat Cell Biol 2011, 13:434-446.

92. Garzon R, Calin GA, Croce CM: MicroRNAs in Cancer. Annu Rev Med 2009, 60:167-179

93. Cho WC: MicroRNAs: potential biomarkers for cancer diagnosis, prognosis and targets for therapy. Int J Biochem Cell Biol 2010, 42:1273-1281.

94. Osaki M, Takeshita F, Ochiya T: MicroRNAs as biomarkers and therapeutic drugs in human cancer. Biomarkers 2008, 13:658-670.

95. Bartels $\mathrm{CL}$, Tsongalis GJ: MicroRNAs: novel biomarkers for human cancer. Clin Chem 2009, 55:623-631.

96. Heneghan HM, Miller N, Kerin MJ: MiRNAs as biomarkers and therapeutic targets in cancer. Curr Opin Pharmacol 2010, 10:543-550.

97. De Smaele E, Ferretti E, Gulino A: MicroRNAs as biomarkers for CNS cancer and other disorders. Brain Res 2010, 1338:100-111.

98. Fichtlscherer S, De Rosa S, Fox H, Schwietz T, Fischer A, Liebetrau C, Weber M, Hamm CW, Roxe T, Muller-Ardogan M, et al: Circulating microRNAs in patients with coronary artery disease. Circ Res 2010, 107:677-684.

99. Huang Z, Huang D, Ni S, Peng Z, Sheng W, Du X: Plasma microRNAs are promising novel biomarkers for early detection of colorectal cancer. Int J Cancer 2010, 127:118-126.

100. Brase JC, Wuttig D, Kuner R, Sultmann H: Serum microRNAs as noninvasive biomarkers for cancer. Mol Cancer 2010, 9:306.

101. Krutzfeldt J, Rajewsky N, Braich R, Rajeev KG, Tuschl T, Manoharan M, Stoffel M: Silencing of microRNAs in vivo with 'antagomirs'. Nature 2005, 438:685-689.

102. Gonzalez S, Pisano DG, Serrano M: Mechanistic principles of chromatin remodeling guided by siRNAs and miRNAs. Cell Cycle 2008, 7:2601-2608.

103. Lanford RE, Hildebrandt-Eriksen ES, Petri A, Persson R, Lindow M, Munk ME, Kauppinen S, Orum H: Therapeutic silencing of microRNA-122 in primates with chronic hepatitis C virus infection. Science 2010, 327:198-201.

104. Stenvang J, Petri A, Lindow M, Obad S, Kauppinen S: Inhibition of microRNA function by antimiR oligonucleotides. Silence 2012, 3:1.

105. Rossi JJ: New hope for a microRNA therapy for liver cancer. Cell 2009, 137:990-992.

106. Bader AG, Brown D, Winkler M: The promise of microRNA replacement therapy. Cancer Res 2010, 70:7027-7030

107. Zampetaki A, Kiechl S, Drozdov I, Willeit P, Mayr U, Prokopi M, Mayr A, Weger S, Oberhollenzer $F$, Bonora $E$, et al: Plasma microRNA profiling reveals loss of endothelial miR-126 and other microRNAs in type 2 diabetes. Circ Res 2010, 107:810-817

doi:10.1186/1479-5876-10-228

Cite this article as: Chen et al.: Roles of microRNA on cancer cell metabolism. Journal of Translational Medicine 2012 10:228. 